\title{
Extension and deepening of new media development to the traditional communication theory from the perspective of "Chaijing Event"
}

\author{
Chen Juan \\ (2015 annual project of Federation of Humanities and Social Sciences in Henan: view extension \\ and deepening of new media development to the communication theory from the perspective of \\ "Chaijing Event", project number: SKL-2015-568)
}

\section{Key words: "Chai Jing Event"; New media; Communication theory; Extension and deepening}

\begin{abstract}
As soon as the new media represented by "network" has appeared, it had a huge influence. With the growing emergence, new media greatly extends the human communication ability, has more and more audience, also changes the relationship between the media and the audience, and even has a disruptive influence on traditional media in some level. At the same time, mass communication properties and interpersonal communication characteristics of new media are more profound and intriguing. As the communication work with explosion level in 2015, "Under the Dome" has been done by the development of new media, and eventually has been ruined, which is the so-called "Either success or failure boils down to the same person." How did the development of new media affect the trend of documentary? From "Chai Jing Event", we can find some different peculiarities of new media from communication theory before. The paper attempts to take "Chai Jing Event" as an example, summarizes the impact and change of new media development on the traditional communication theory from the perspective of communication theory, and analyzes extension and deepening of it to the classical communication theory.

"Under the Dome", the public documentary taken by Chaijing at her own expense and lasting 103 minutes and 55 seconds, has get 300 million crazy hits within four days and called the phenomenal video which first has the most widely spread in 2015, the biggest impact with the use of new media by many people in the media. In the meantime, it also brings us too many feelings. Someone was shocked by the content of documentary, and someone was also puzzled by a mixed bag of reviews online, in the end, the documentary disappeared in people's sight, then we call the whole process "Chai Jing Event". New Year is coming, and "Under the Dome" has long gone, but haze still enters the room unexpectedly, we should look back "Under the Dome" and "events" caused by it and think something combining with the development characteristics of new media era, making it useful for the future.
\end{abstract}

\section{Expansion of "Lasswell program" 5W mode}

Who-specialization and diversification of communication subject

New media makes the threshold of information transmission reduce almost to zero, a growing number of subjects and agencies begin to act as the role of the communicator, and to join the information production and transmission process. With the aid of mining and analysis for the cloud trajectory big data of individual behavior, new media service providers greatly improve the refinement and specialization of editorial content. The promulgators of video "Under the Dome" are both the CCTV's team of Chai Jing such as Fan Ming, Li Lun, Hao Junying, and Mr Luo's hammer team at the same time, in addition, some masters in the field of micro-blog, known, investigative reporters also serve as the talents, such as Shi Hang, Ding Wenshan, Wang Tao, etc. The copywriting, filming and production of the work all used the Internet thinking, which had absolutely first-class professional level on the details and process, bringing work so much attention and a great influence. 
Say what-rich and diverse content

In the digital new media environment, the professional media organizations translate from a production institution single content gradually into comprehensive content production and distribution institution with a collection of texts, images, audios, videos, animations, e-books, and 3D TV and movies, so that the audience can see the all-around information in various forms when understanding a news event, a full range of.

"Under the Dome" applied the represented knowledge, visual data, anthropomorphic science, and graphical information to describe and popularize the fog knowledge. The entire video used the Internet large data to the extreme, graphs, tables, maps were unprecedented used for so many times, and video site utilized new TED lecture form, large screen display, flash animation, shooting drones and science and fiction special effects, then these rich and various information strongly attracted viewers.

In what channel - new type and compound of transmission medium, points out

In the era of big data, new communication channels have appeared in different forms in succession, merged with each other, forming a three-dimensional, composite transmission network. Channels issue of "Under the Dome" take new media video site in full coverage mode, and publish first in People's Daily online and Youku and Tudou platform, then almost all of the video website has followed, and Tencent video, Youtube video and other video sites have recommended it in the homepage, within 24 hours the video on Youku received 6 million hits and more than 60000 times praises, soon "Under the Dome" spread quickly in WeChat circle of friends, through the social networking site and explosive chain transmission, broadcast quantity within 48 hours of entire network achieved a staggering 200 million person-time, showing the tremendous power of composite and new media.

To whom- fragmentation and personalization of audience

In the new digital media age, the audiences are no longer a unified whole, the emergence of a variety of dispersed network communication platform, such as search engines, portals, instant messaging tools, community sites, micro-blog, wechat and others greatly subdivided network media audience, who are split into pieces, the mass media in "cloud communication era" are more personalized and interactive. China has 630 million Internet users, 500 million weibo and weChat users, and the amount of information everyday is over 20 billion. "Under the Dome" popularity is inseparable with fragmented network audiences. By March 1 at 9 am, statistical data of the major video sites playing "Under the Dome": Tencent video 74.26 million, support for 4316, against for 365; Sohu video 2.03 million, support for 4506, against for 101; Iqiyi 1.09 million, support for 18110, against for 939; Phoenix video 690 000, support for 530, against for 10; Tudou 630,000 with 39,444 comments, a total of $99,390,000$ plays, support for 150,000 , against for 1471 . Data effectively proves this point.

With what effects - immediacy and extensification of communication

The spread and feedback of the new media age is timely and quick, so it is possible to achieve a wider communication effect than ever before. Once video released, a SMW comment, People's Daily online and others almost at the same time carried the review and interview. Then, more comprehensive and professional praise and deeper and more detailed query falls and rises one after another. This 103-minute documentary inspired voice of all kinds of people, some people saw the seriousness of the haze, someone saw the great love from Chai Jing, someone saw the responsibility ethics, someone saw the absence of government, also some people saw the marketing case...Phoenix TV commentators Cao Jingxing also think that we should thank Chai Jing, and in NPC \& CPPCC each member, on behalf of the two sessions, attend officials should look the video again. In the interview People's Daily published on that day, Chai Jing also said, she has sent interview data and letters to the National People's Congress being revised "law on the prevention and control of atmospheric" and team members being making national oil and gas system reform scheme, and get a positive feedback, so the communication effect gets further expansion. 


\section{"Spiral of silence" theory lose efficacy}

New media vastly extends human ability, and human ability in perceiving, exploring, expressing and communicating internal and external world magnified in geometrical times, then increasing ability makes more and more social individuals become the important links among the network transmission. Everyone is the recipient of information, as well as the publisher of information, which makes the information more diversified, opinion expression more freedom. Because of the change of media condition and social environment, motivation for convergence behavior of the advantages opinions is no longer an absolute constant, and personal fear of social isolation is disappearing, then convergence behavior for most or advantage opinions produced by the "fear" begins to weaken, finally "spiral of silence" theory starts to lose efficacy under the network environment.

Chai Jing's "Under the Dome" once broadcast has become a common topic. In an era of new media in power, the people feelings of "Under the Dome" and the resulting discussion are unlike in the past era of traditional media as unanimous, a new communication mode brings freedom of expression to make people inevitably all talk at once and consider them always right. Approbation are similar, the original editor "topics in focus" Zhuang Yongzhi praised for Chai Jing, zhihu boy from environment department posted a message to express admiration, and Cui Yongyuan, Yao Chen, Yuan Li and other micro-blog big V gave supports. However, criticism and questioned also varied, the developmental indicated mockery, the modern show disdain, the technical expressed dissatisfaction, and the left denoted antipathy, documentary production and dissemination way also caused the questioning, and then how is relationship between infant congenital tumors and haze ? Whether the documentary arouses over human emotion and loses objectivity? All in all, one thousand audiences has one thousand Hamlet, we heard a variety of sounds overturning "spiral of silence" theory.

\section{"agenda-setting" theory is endowed with new meaning}

In the era of new media, agenda setting theory is endowed with new meaning, as a result of quite fast propagation speed of information in new media age, increasing the reported intensity and frequency of events could be easily done. Meanwhile, individual initiative and freedom of network brought by the new media make the mass communication and interpersonal communication intertwined, and the report object and the audience can establish a direct connection with interactive technology, which is very beneficial to improve the degree of attention to an event. But it doesn't mean that agenda-setting function of traditional media fails in the era of new media, traditional media endow new media with authority, and new media feed the traditional media with its technical advantages in turn, making traditional media information more in line with public opinion. Both new media and traditional media can "set agenda each other".

The release mode of "Under the Dome" is a model for fusion of the traditional news media and new media information. After Chai Jing "Under the Dome" online, news and video links for the first time introduced it in the home page and first screen of Tencent, and set up news feature with in-depth reports synchronously, then Tencent news client also recommended it in important entrance for the convenience of users quickly and roundly to watch and made the different decomposition for the news main points. At the same time, the documentary announced in Youku, Sohu, Letv all influential video websites and public broadcasting effects were beyond imagination. In addition, the release time of is also just right, which chose the collisions period between the traditional media and new media, neutral topic of the first week of Spring Festival break, also before the two conferences. Predictably, in subsequent national two sessions, governing haze subject naturally become the hottest topic. It is worth noting that, in the explosive spread of "Under the Dome", traditional media still have played an important orientation and authority role. Soon after Chai Jing documentary published, director of the national energy administration is committed to vigorously promote the new energy revolution, China news broadcasted the "CPPCC perspective: 
China will make the addition and subtraction of the pollution treatment from the surface to source", Xinhua news agency reported on February 28 "law China, walking sonorous - see a new start of "comprehensive government for the country according to law" during two sessions, and the People's Daily website published an interview to support Chai Jing all their best. The publishing process of "Under the Dome" is a successful example that new media and traditional media conducted jointly "agenda setting ".

\section{The "gatekeeper" theory needs to be deepened}

The rise of new digital media let people get unprecedented freedom, so that everyone becomes a node in the network information dissemination, a body of information publishers and receiver, and this freedom has broken the monopoly on information release of traditional media. With the development of social networking platforms such as weibo, weChat and the emergence of community sites, "gatekeeper" gradually shows a universal trend; it has put forward higher requirements to the "gatekeeper", and the "gatekeeper" effect is more complex and more unpredictable than ever, then "gatekeeper" behavior needs to be more and more constrained by new laws and regulations and network moral. So the media age should re-examine the integrating point of "gatekeeper" theory and new media public opinion, to deepen and expand the gatekeeper theory.

After "Under the Dome" video spreads through the major sites, all points of view difference with each other by reason of the large degrees of freedom from media opinion expression platform. The public issue "fog" is far away from the point after the quarrel between the "Chai fans" and "Chai anti-fans", and network public comment on public issues themselves no longer, but focus on producer's motivation, moral and her private life, Whether Chai Jing smokes or not ? Whether she has been a third party? Whether she drives a large displacement car?......These "pseudo-criticism" to compete for personal voice and get sense of presence has obviously deviated from the original intention of "under the dome", and they put the existential issue "haze" aside and turned to Chai Jing personal moral judgment. In the new media environment, "public opinion explosion" usually occurs when a large number of people focus on one subject, and people mixed up with the good and evil speak and quarrel, then the topic will be constantly amplified, endosmic "sand" will be more and more, audience will be more easily lack of rational and emotional thinking into the parroting cycle, so that the situation gradually becomes uncontrollable, off the topic and losing the meaning of communication. So, on March 6, the Central Propaganda Department issued the "ban order", the full version of "Under the Dome" removed off each website, and the link became invalid on Youku and various video broadcast platforms, then Chai Jing interview published in the People's Daily online is deleted, finally "Under the Dome" eventually fade out the line of people sight.

\section{The strengthening of "use and satisfaction" theory}

As the media environment changes with each passing day, "use and satisfaction" theory continues to be strengthened. Different from satisfaction of traditional media, new media tools that new technology gave rise to provide with more satisfaction of traditional demand, and digital new media provides the participation opportunity to meet the different needs for each audience: whether to create blogs, post micro-blogs, or join weChat, use Facebook, satisfy this basic requirement that the audiences equally participate in information transmission and release; New media also gradually showed a multimedia trend, and users can obtain the information in the form of word, MMS, picture, video to absorb the waste time, then they can take out the mobile phone, Ipad to get the information they want to see and publish information. In interactive information environment, the audiences will achieve many-to-many information interaction with other audiences, and using new media to share with others can meet the needs of audience contribution and sharing; meanwhile, the media users can produce any data and information content according to their own individualities, meeting the personalized needs. From weibo to weChat, from blogs to video sharing sites, the new media landscape booms rapidly, and "uses and gratifications" of new media has been formed. 
For the use of the media, "under the dome" use media with many links and multiple forms to alternate and cooperate to complete the communication process, such as information excavation in the form of UGC, organization and launch of derivative topic, multiple forms of editing power and follow-up of multiple media forms...In the whole process, various new media platforms have been utilized and played a huge role. Information diffusion of new media and multidirectional interactive features build a civil channel for "under the dome", and people actively participate in environmental protection public welfare undertakings that documentary advocated with the use of new media. After the broadcast of "under the dome", many public picked up the camera in their hands and took enterprise pictures about environment pollution around us, then forwarded them to 12369 official weibo, causing more people to discuss. Therefore, the documentary used operation convenience and using universality of new media to realize rapid spread, giving rise to widespread social concern within a very short time. This is the best example that "use and satisfaction theory" is enhanced.

\section{The "social responsibility theory" is necessary}

New media extends the spread ability of ordinary individual while magnifying humanity, the irrational factors in the human nature also makes new media rapidly become a distributing centre of rumors of and a place storm generated, which reflects the people absence of responsibility in the new media environment to a certain extent. Communication ability and the sense of responsibility have not been synchronously extended, while unilateral capacity growth eventually will turn into a kind of unlimited violence, thus deconstructing the openness and the public of the new media platform.

In 150 minutes, Chai jing will show the "haze" to the public widely, deeply and comprehensively as far as possible, letting everybody know how to do later, and information Chai Jing want to convey has arrived. But, why this rapidly fermented "public issues" still turns into yesterday's story under the ban? Due to the lack of social responsibility of the audience, quarreling is unceasing, onlookers are numerous, but the actors are few, filled with the argument among groups between ethics and amorality, fans and the fans, conspiracy and anti-conspiracy. Groups have spent too much time to talk about, appreciate, or even make up and consume Chai Jing herself without proofs rather than the haze and the environmental protection itself. Famous French scholar Tasman Taff • Le Pen in his masterpiece "the mob-mass psychological study" thought: "The group often reflects the emotional characteristics with infection, and individuals in the group and their behaviors are in the complete infection and dominance of a collective unconscious emotion, then personal intelligence and rational judgment have disappeared completely, so that people are very easy to become violent." ${ }^{[1]}$ The brawl in the network group is large, but it is difficult to see a deeper, more creative works with more comprehensive analysis in environmental protection subject than "Under the Dome", and we also can't hear any constructive suggestions. Thus, there is still a distance away from the civil society. We should further increase the responsibility education specific to the individual, and melt it into the responsibility consciousness to foster more conscious responsibility main body. Let the expanding personal ability and the growing sense of social responsibility brought about by new media balance each other, it could form a more powerful and orderly new media environment.

When we face the haze days again today, what we should do is to think how to act, to monitor environmental pollution real-time and effectively, to spur the government to introduce stronger environmental policies, to write deeper analysis haze papers, and to make more sophisticated haze documentary than that of Chai Jing team, only in this way, we just will be likely to make public issues become consensus opinions, and then convert them to citizen will and affect social behaviors, finally change the state of the environment. 


\section{References}

[1] Tasman Taff - Le Pen. Mob-mass psychological research. [M]. Beijing: New World Press, 2010.89

[2] Chai Jing "Under the Dome" detonated video from the media. www.centrechina, com/finance/31231.html

[3] Tai media, Journalism that Chai Jing Under the Dome" may and should rewrite www.tmtpost.com/198613.html

[4] "Under the Dome" at issue ": melee between "new media"and "old moral" Shanghai Caifeng, 2015.4

[5] Ye Chen, self-media transmission in the Web3.0 age - with Chai Jing "Under the Dome" as an example, News World, 2015.4

[6] Gong Jun, the fusion road of traditional media and new media in the Internet age. News Communication. 2014.4

About the author: Chen Juan, female, born in September 1980, Han, native of Hubei, Master of television journalism of Huazhong University of Science, teaching at the Yellow River science and technology institute, school of journalism, lecturer, engaged in the study of film and television culture, staff residential area of Huanghe Science and Technology College, Zhengzhou City, Zijin Road No. 666 